\title{
ÁNALISE DE ÁGUA dO AFLUENTE dO CORRÉGO DO VEADO EM PRESIDENTE PRUDENTE - SP
}

\author{
WATER ANALYSIS OF THE CORRÉGO DE LA VEEGA WATER IN PRUDENT \\ PRESIDENT - SP
}

Bruno Pereira Sossai ${ }^{1}$; João Victor Carvalho de Andrade $^{2}$; John Lenon Benedito da Silva ${ }^{3}$, Laís Gabriela Soares Marques, ${ }^{4}$, Lukas Fabiano Artuso ${ }^{5}$, Miguel Marrion Souza ${ }^{6}$, Elson Mendonça Felilici Nelissa Garcia Balarim ${ }^{8}$

\author{
${ }^{1}$ Universidade do Oeste Paulista - UNOESTE, Curso de Engenharia Ambiental e \\ Sanitária, Presidente Prudente, SP - Brasil \\ E-mail: bruno_sossai.live@outlook.com
}

\begin{abstract}
RESUMO - Os corpos hídricos sejam de pequeno ou grande porte tem uma grande importância dentro de um ecossistema, pois estão ligados diretamente ao equilíbrio ecológico, o presente estudo teve como objetivo analisar amostras de água diversos pontos de um corpo hídrico presente dentro do perímetro urbano, sua metodologia foi advinda do Standard Methods For The Examination Of Water \& Wastewater, um dos livros mais bem-conceituados para analises de água, os resultados foram satisfatórios trazendo respostas que mostram que o corpo hídrico tem capacidade para vida aquática, e a conclusão é de que se requer maiores cuidados com esses recursos que estão diretamente ligado a vida humana.
\end{abstract}

Palavras-chave: Corpo Hídrico, Analises, Efluente, Vida Aquática, Impacto.

\begin{abstract}
The water bodies are of small or large size have a great importance within an ecosystem, since they are connected directly to the ecological balance, the present study had as objective to analyze water samples several points of a hydric body present within the urban perimeter, its methodology was derived from the Standard Methods for the Examination of Water and Wastewater, one of the most well-regarded books for water analysis, the results were satisfactory with answers that show that the water body has the capacity for aquatic life, and the conclusion is that requires greater care with these resources that are directly linked to human life.

Keywords: Hydride body, Analysis, Effluent, Aquatic Life, Impact.
\end{abstract}

\section{INTRODUÇÃO}

A água é um recurso estritamente natural, onde todos os seres vivos presentes na Terra necessitam deste bem. A preservação deste é de suma importância para que se possa ocorrer o equilíbrio ecológico, desde os tempos mais primitivos a água sempre teve a função de mover povos mesmo que seja de forma totalmente involuntária, mas que sempre levou os povos a evolução e a chegarmos nos dias atuais com tudo que temos.

A qualidade da água de uma microbacia pode ser influenciada por diversos fatores e, dentre eles, estão o clima, a cobertura vegetal, a topografia, a geologia, bem como o tipo, o uso e - manejo do solo da bacia hidrográfica (VAZHEMIN, 1972; PEREIRA, 1997).

Segundo TUNDISI (1999), alterações na quantidade, distribuição e qualidade dos recursos 
hídricos ameaçam a sobrevivência humana e as demais espécies do planeta, estando o desenvolvimento econômico e social dos países fundamentados na disponibilidade de água de boa qualidade e na capacidade de sua conservação e proteção.

A preservação desse bem (ÁGUA) é extremamente importante, pois a água é necessária para a sobrevivência no nosso planeta, e ao longo de anos no decorrer da evolução do homem os recursos hídricos vêm sendo impactado das mais diversas formas, como por exemplo, a sua contaminação por lançamento clandestino de esgoto, disposição de resíduos sólidos em recursos hídricos.

Segundo FREITAS \& ALMEIDA (1988), as principais fontes de contaminação por meio da atividade humana, são em geral realizadas por despejos de efluentes sejam domésticos e industriais, e ao chorume, resultado dos aterros de lixo na qual contaminam os lençóis freáticos com microrganismos patogênicos.

A contaminação dos lençóis freáticos chega até as nascentes e a população, e para isso exige-se a RESOLUÇÃO N 430, DE 30 DE MAIO DE 2011 "Dispõe sobre as condições e padrões de lançamento de efluentes, complementa e altera a Resolução no 357 , de 17 de março de 2005, do Conselho Nacional do Meio Ambiente-CONAMA". Basicamente o lançamento de efluente direcionado ao corpo hídrico da área em estudo, é oriundo do esgoto doméstico de sua própria micro bacia, sendo então o único corpo hídrico apto a recepção do mesmo, o afluente em questão é definido como classe 4 pelo Decreto de № 10.755 de 22 de novembro de 1977.

O objetivo desse estudo foi descobrir se havia algum tipo de agente prejudicial a vida aquática nesta microbacia tendo como base alguns parâmetros do IQA (Índice de Qualidade das Águas) e DQO.

\section{MATÉRIAIS E METODOS}

Foi realizada 1 coleta em 4 pontos distintos no córrego com o objetivo de analisar os parâmetros físico-químicos da água, tais como, $\mathrm{pH}$, temperatura, turbidez, DQO e fósforo, essas amostras foram armazenadas em frascos com um volume de $500 \mathrm{~mL}$.

O ponto de coleta 1 foi definido e coletado na maior nascente do afluente e no ponto mais alto, inicio do córrego, local onde continha lançamento de efluente clandestino, localizada através de GPS na latitude $\left(22^{\circ} 07^{\prime}\right.$ $\left.34.33^{\prime \prime} \mathrm{S}\right)$ e longitude ( $\left.51^{\circ} 26^{\prime} 32.27^{\prime \prime} \mathrm{O}\right)$, o ponto 2 foi coletado a jusante, em um ponto onde se encontrava uma intersecção de afluentes, na qual um era do rio principal e o outro uma nascente da microbacia, esse ponto localiza-se na latitude ( $22^{\circ} 07^{\prime} 22.26^{\prime \prime}$ S) e longitude ( $51^{\circ} 26^{\prime} 37.93^{\prime \prime} \mathrm{O}$ ).

Para o ponto 3 o critério foi a presença de um canal e um viaduto, onde seria necessária uma coleta de amostra antes desse viaduto, localizando- o em latitude $\left(22^{\circ} 07^{\prime} 5.74^{\prime \prime} \mathrm{S}\right)$ e longitude $\left(51^{\circ} 26^{\prime} 37.35^{\prime \prime}\right.$ O), no ponto 4 se encontra no exutório da microbacia do estudo na latitude $\left(22^{\circ} 06^{\prime} 47.88^{\prime \prime} \mathrm{S}\right)$ e longitude $\left(51^{\circ} 26^{\prime}\right.$ $37.35^{\prime \prime}$ )), o critério foi a necessidade de um ponto na foz dessa microbacia, local onde há descarte de efluente clandestino.

Mapa 1. Pontos de coleta as análises de água.

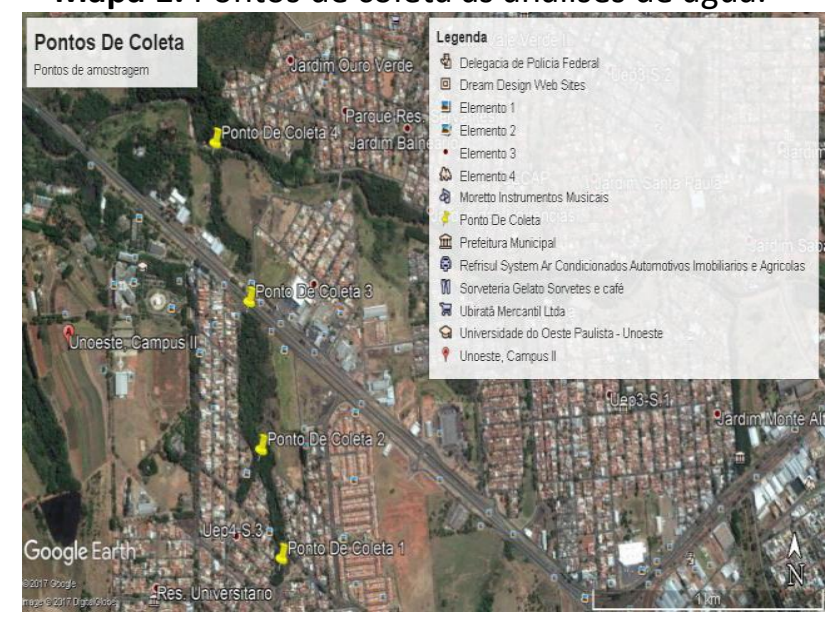

Fonte: Autores (2017)

As amostras após serem coletadas e armazenadas, foram levadas para o laboratório realizando-se as análises, onde foram determinados $\mathrm{o} \mathrm{pH}$ de cada amostra, a temperatura, a turbidez, e em seguida as amostras foram preparadas para analisar a DQO, na qual foi reduzido o $\mathrm{pH}$ para 2 das mesmas para aumentar sua duração como técnica de preservação para aumentar o período de análise de até 28 horas para 28 dias, logo depois das análises de DQO realizamos a de Fósforo.

\section{ANÁLISES FÍSICO-QUÍMICAS}

O potencial Hidrogeniônico $(\mathrm{pH})$ indica a acidez, neutralidade, alcalinidade de uma solução aquosa por meio da medição da presença de íons de Hidrogênio $\mathrm{H}+$. A Temperatura um parâmetro que influência a atividade biológica, para a determinação de ambas, foi utilizado o pHmetro 
para a análise, chamado de método Potenciométrico, onde se utiliza eletrodos com mercúrio em seu interior demonstrando o potencial hidrogeniônico das amostras, podendo variar seu valor de 1-14 na qual quanto mais próximo do 1 mais ácido, e quanto mais próximo do 14 menos ácido, mais básico.

A Turbidez indica a presença de partículas sólidas em suspensão na água devida à dissolução de rochas ou despejo de efluentes, para isso foi utilizado o turbidimetro para a análise, na qual quanto menor a passagem de luz na amostra maior a turbidez, mostrando os sólidos em suspensão.

A Demanda Química de Oxigênio (DQO) é um parâmetro que mede a quantidade de oxigênio necessário para consumir a matéria orgânica presente na água, antes da análise foi realizada uma técnica de preservação, e o método de análise foi feito através da adição de soluções catalíticas (Ácido Sulfúrico e Sulfato de Prata) e digestora (Dicromato de Potássio), onde o Dicromato é usado como biodigestor a uma alta temperatura, essas reações formam o cromo - III e sua quantidade formada demonstra a mesma quantidade da DQO, e a leitura é feita em espectrofotômetro medindo o grau de absorbância da amostra.

Fósforo é um parâmetro que acelera o processo de eutrofização nos cursos hídricos e para ele foi usada a metodologia de Redução com Ácido Ascórbico e a leitura foi feita pelo espectrofotômetro medindo o grau de absorbância da amostra.
Quadro 1. Parâmetros analisados e metodologia utilizada para a realização dos experimentos.

\begin{tabular}{|c|c|c|}
\hline Parâmetro & Método & Referência \\
\hline $\mathrm{Ph}$ & Potenciométrico & $\begin{array}{l}\text { SMWW, 21a } \\
\text { Edição, } \\
\text { Método } 4500 \\
-\mathrm{H}+2\end{array}$ \\
\hline Turbidez & Nefelométrico & $\begin{array}{l}\text { SMWW, 21 a } \\
\text { Edição, } \\
\text { Método } 2130 \\
\text { - B }\end{array}$ \\
\hline Fósforo & $\begin{array}{l}\text { Redução de } \\
\text { Ácido Ascórbico }\end{array}$ & $\begin{array}{l}\text { SMWW, 21a } \\
\text { Edição, } \\
\text { Método } 4500 \\
\text { - P-F }\end{array}$ \\
\hline DQO & $\begin{array}{l}\text { Método do } \\
\text { Refluxo Fechado }\end{array}$ & $\begin{array}{l}\text { SMWW, 21ạ } \\
\text { Edição, } \\
\text { Método } 5200 \\
\text { C }\end{array}$ \\
\hline
\end{tabular}

\section{RESULTADOS E DISCUSSÃO}

Quadro 2. Resultados obtidos por análises laboratoriais dos parâmetros.

\begin{tabular}{|c|c|c|c|c|}
\hline Amostras & A1 & A2 & A3 & A4 \\
\hline $\mathrm{pH}$ & 6,8 & 6,99 & 7,12 & 7,34 \\
\hline Temperatura & $26,4^{\circ} \mathrm{C}$ & $26,3^{\circ} \mathrm{C}$ & $26,7^{\circ} \mathrm{C}$ & $26,8^{\circ} \mathrm{C}$ \\
\hline \multirow{2}{*}{ Turbidez } & 12,5 & 3,54 & 1,43 & 1,75 \\
& $\mathrm{NTU}$ & $\mathrm{NTU}$ & $\mathrm{NTU}$ & $\mathrm{NTU}$ \\
\hline \multirow{2}{*}{$\mathrm{DQO}$} & 127,33 & 100,66 & 87,33 & 69,33 \\
& $\mathrm{mg} / \mathrm{L}$ & $\mathrm{mg} / \mathrm{L}$ & $\mathrm{mg} / \mathrm{L}$ & $\mathrm{mg} / \mathrm{L}$ \\
\hline \multirow{2}{*}{ Fósforo } & 0,4828 & 0,5201 & 0,3851 & 0,1983 \\
& $\mathrm{mg} / \mathrm{L}$ & $\mathrm{mg} / \mathrm{L}$ & $\mathrm{mg} / \mathrm{L}$ & $\mathrm{mg} / \mathrm{L}$ \\
\hline
\end{tabular}

Fonte: Autores, 2017.

\section{1. $\mathrm{pH}$}

Os resultados das análises de $\mathrm{pH}$ são satisfatórios, pois segundo a Resolução Conama № 430/11 na Seção II, Das Condições e Padrões de Lançamento de Efluentes no Art. 16, inciso I, alínea a, onde diz que o $\mathrm{pH}$ dentre 5 a 9 estão todos dentro de uma faixa aceitável para a vida aquática.

ESTEVES (1998) o pH é muito influenciado pela quantidade de matéria morta a ser decomposta, sendo que quanto maior a quantidade de matéria orgânica disponível, menor o $\mathrm{pH}$, pois para haver decomposição desse material muitos ácidos são produzidos.

$\mathrm{O}$ pH em todos os pontos estão próximos da neutralidade, isso significa que existe pouca matéria orgânica dentro do corpo hídrico a ser 
decomposta, a matéria orgânica dentro de um corpo d'água influencia diretamente na faixa de $\mathrm{pH}$ do local.

\subsection{Turbidez}

Os resultados das análises de turbidez trazem um índice baixíssimo de incidência em todos os pontos, estes valores supõem que o rio esteja enquadrado como classe 2 , pois o NTU pode ir até o valor de número 100 segundo o que está resolução Conama 375/2005 com atualizações na Resolução Conama 430/2011. Segundo o Decreto 10.755/1977 do Estado de São Paulo, o córrego em questão no estudo estaria enquadrado na classe de no 4, os resultados contrapõem está condição, pois sabese dos processos naturais que ocorrem no meio ambiente e este corpo hídrico pode ter se modificado ao longo destes 40 anos.

No ponto 1 a turbidez estava mais acentuada quanto as outras devido a canalização da nascente de onde saem não só agua como também alguns outros resíduos advindos de outras regiões, essa poluição afeta diretamente quem possivelmente faz o uso dessa água, no ponto é importante ressaltar que mesmo sendo baixo o valor da turbidez, existe um descarte de efluente clandestino o que faz com que mude as características do córrego.

Para OLIVEIRA, NETO, et al. (2008) em áreas que apresentam elevada turbidez, as partículas podem acomodar uma grande quantidade de poluentes e até microrganismos patogênicos.

\section{3. $D Q O$}

A DQO não está presente no IQA (Índice de Qualidade da Água), porém é importante realizar a análise, pois traz as informações sobre a quantidade de oxigênio necessária para fazer a degradação de matéria orgânica presente na água do corpo hídrico em estudo. Assim sendo os resultados obtidos acerca da análise de DQO mostra que no ponto 1 (A.1) tem um índice maior, devido a presença de efluentes clandestinos, sem tratamento, direto no corpo hídrico. 0 ponto 2 e o ponto 4 apresentam mesma característica do descarte de efluente clandestino.

A DBO (Demanda Bioquímica de Oxigênio), pode entrar em discussão mesmo somente com a análise de DQO pois a DBO segundo a literatura a DBO pode ser descrevida como DQO x 0,5, assim sendo, os valores da DBO seriam para um córrego de classe 4 , segundo a Resolução Conama 375/2005 os córregos de classe 1 poder ter até $3 \mathrm{mg} / \mathrm{L}$ de DBO, e os de classe 2 até $10 \mathrm{mg} / \mathrm{L}$, os córregos de classe 4 não tem uma descrição especifica para este tipo de situação.

\subsection{Fósforo}

O Fósforo é um dos parâmetros presentes no IQA, ele se torna criticamente importante, pois a sua presença em excesso no corpo hídrico, principalmente em ambientes lênticos, pode ocasionar eutrofização do meio aquático, tendo em vista que o fosforo é um elemento necessário para o desenvolvimento de algas. A partir dos resultados obtidos nas análises é possível dizer que o ponto 2 tem maior presença de fósforo, pois no dia da coleta da amostra, criou-se uma hipótese de despejo de efluente no corpo hídrico, devido ao efeito detergente encontrado no local escolhido para coleta da amostra, acredita-se que esse efluente é provindo das ruas do loteamento em questão.

Com base na Resolução Conama 375/2005 os córregos classe 4 não tem descrição especifica para este quesito, mas levando em consideração se o córrego fosse classe 2 os níveis estariam bem acima do normal, uma vez que em córregos classe 2 os níveis de fósforo ideias tem que ser em torno de $0,05 \mathrm{mg} / \mathrm{L}$.

\section{CONCLUSÃO}

Advindo dos resultados obtidos a partir das análises laboratoriais, concluísse que, o corpo hídrico presente nesta microbacia não está com grandes níveis de degradação, porém é necessária uma maior fiscalização dos órgãos ambientais, sejam da prefeitura municipal quanto estadual para que haja uma maior conservação destes recursos, pois, em alguns pontos de coleta para as análises de água do corpo hídrico há o descarte de efluente clandestino assim como também da rede coletora de "esgoto" do perímetro urbano via meio fio e guia de sarjeta que canalizam por meio de galerias essa água que pode conter sabão e até óleo comum ou de motores. 


\section{REFERÊNCIAS}

BRASIL. Decreto 10.755 de 22 de novembro de 1977. Disponível em: < http://www.daee.sp.gov.br/legislacao/arqu ivos/835/decreto_10755.pdf> Acesso em 13 de Agosto de 2018

BRASIL. Ministério Do Meio Ambiente, Conselho Nacional Do Meio Ambiente - Resolução Conama Lei Federal De № 430/11 - disponível em

<http://www.mma.gov.br/port/conama/legiabre. cfm?codlegi $=646>$ acesso em 10 de agosto de 2018.

ESTEVES, F. D. A. Fundamentos de Limnologia. Interciência, Rio de Janeiro, n. 2aㅗ, 1998.

FREITAS, M.B; ALMEIDA, L.M. Qualidade da Água Subterrânea e Sazonalidade De Organismos Coliformes em Áreas Densamente Povoadas Com Saneamento Básico Precário. Disponível em: <file:///C:/Users/PC/Desktop/22294-804581-PB.pdf> Acesso em: 07 de Agosto de 2018

OLIVEIRA, V. D. M. et al. Avaliações Físicas, Químicas e Biológicas da Microbacia do Córrego Modeneis em Limeira - SP. Engenharia Ambiental, Espirito Santo do Pinhal, v. 5, n. 1, 2008.

PEREIRA, V.P. Solo: manejo e controle de erosão hídrica. Jaboticabal: FCAV, 1997

VAZHEMIN, I.G. Chemical composition of natural waters in the VYG river basin in relation to the soil of Central Karelia. Soviet Soil Science, Silver Spring, v.4, n.1. 1972.

TUNDISI, J.G. Limnologia do século XXI: perspectivas e desafios. São Carlos: Suprema Gráfica e Editora, IIE, 1999. 